
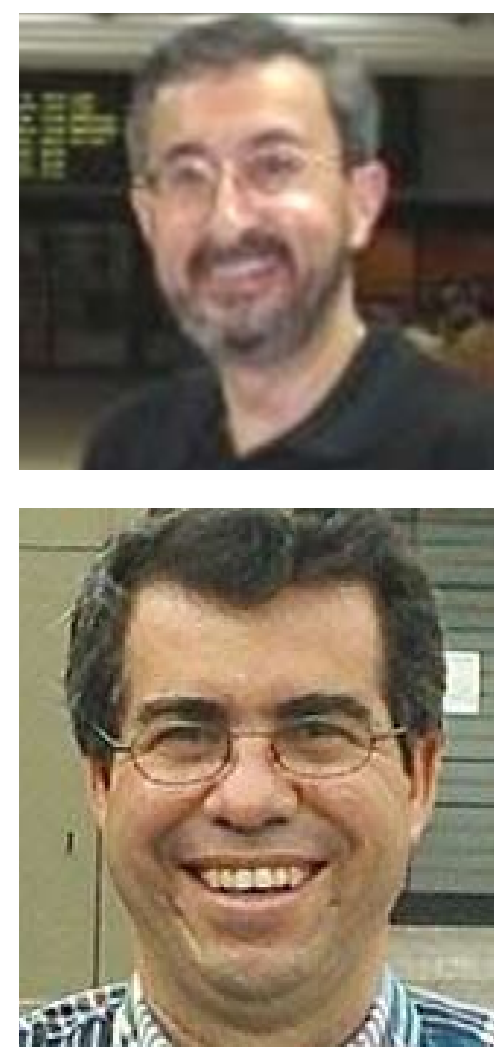

\section{La reflexión sobre}

la educación puede plantearse desde distintas perspectivas filosóficas. Asumiendo la filosofía narrativa de Paul Ricoeur, el artículo esboza un abordaje narrativo de la educación.

\section{En una "educación narrativa", la construcción del \\ conocimiento que se verifica en el aula aparece asociada a la construcción de la identidad, y, en definitiva, a la vida misma, de todas las personas implicadas en el proceso educativo.} Renunciando a un concepto logocéntrico de inteligencia, se propone educar en una "inteligencia narrativa" que forma a sujetos prudentes capaces de interactuar en contextos tan cambiantes como los actuales, signados por la interculturalidad y el pluralismo de visiones del mundo.

\section{VENTANAS ABIERTAS A LA PEDAGOGIA UNIVERSITARIA}

\section{NOTAS PARA PENSAR LA EDUCACIÓN EN TÉRMINOS NARRATIVOS}

\author{
Tomás Domingo Moratalla* y Pablo Mella s.j."
}

La educación se puede abordar teóricamente con cuantas perspectivas filosóficas existan. Sin embargo, no todas las perspectivas filosóficas responden de modo integral a los diferentes aspectos que entraña la acción humana, signada por la contingencia y la debilidad.

El objetivo de este artículo es presentar una reflexión de la educación en términos narrativos, para aportar en la búsqueda de una teoría más integral de la acción educativa. En muchos ámbitos asistimos a una reducción de la acción educativa a la razón instrumental (Bárcena y Mèlich, 2000), especialmente en estos últimos tiempos siguiendo el mito de la sociedad de la información debido a las nuevas tecnologías.

El presente artículo se apoya en la filosofía de la narración de Paul Ricoeur. Tiene aún un carácter exploratorio, por la cantidad de mediaciones pedagógicas que están en juego en la propuesta. Más que un trabajo acabado, el artículo se presenta como un "reflexionar al andar", para buscar nuevas mediaciones tanto en la práctica docente, como en el diseño curricular.

De qué hablamos cuando decimos educación narrativa? Se puede hablar de educación en términos narrativos, o sencillamente de educación narrativa, a partir de dos enfoques principales: a) Uno didáctico, que consistiría en introducir elementos narrativos en las prácticas educativas. b) Otro curricular, que tomaría en consideración las estructuras narrativas que están en juego en el proceso mismo de educar como un todo.
La perspectiva hermenéutica de Ricoeur nos permite combinar ambas estrategias.

Conviene explicitar o caer en la cuenta del tipo de pensamiento implicado en esta visión de la educación que defendemos. No es lo mismo acercarse al pensamiento en un esquema logocéntrico/racionalista, que hacerlo dentro de una perspectiva narrativa. El logocentrismo piensa que un sujeto solitario puede agotar todos los misterios de la existencia a través de un análisis de tipo proposicional. El positivismo sería el ejemplo más claro de logocentrismo. Ahora bien, más que desechar totalmente uno para optar unilateralmente por el otro, podría postularse como plan investigativo un enfoque de complementariedad. Sin embargo, ahora nos toca abogar y argumentar a favor de la perspectiva narrativa, muchas veces olvidada.

El pensamiento narrativo acoge otros lugares distintos a los de la propia tradición filosófica paraconstruirse. No selimita avivir de supropia historia, sino que vive también, y sobre todo, de otras realidades, disciplinas o experiencias. Adopta una visión de la literatura, y en general, del fenómeno artístico, abierta al mundo y a la vida. De esta manera, el pensamiento narrativo nosedesentiende delmundo, sino quepretende incidir en el mundo de una forma diferente, mostrando posibilidades que el sentido común no alcanza. Sin embargo, la narración tampoco es mera fusión con el mundo existente. Se concibe también como una retirada reflexiva, parauna vuelta posterior sobre el mundo que le provoca a hablar.

Ahora bien, la relación que se puede establecer entre filosofía y narración exige

\footnotetext{
* Doctor en Filosofía. Profesor de Antropología en la Pontificia Universidad de Comillas, Madrid y profesor de enseñanza secundaria en el IES María Zambrano, de Leganés, Madrid. Experto en Paul Ricoeur y traductor de algunas de sus obras.

* Sacerdote jesuita. Doctor en Filosofía Política, Universidad Católica de Lovaina, Bélgica. Director del Instituto Filosófico Pedro Francisco Bonó en Santo Domingo y editor de la revista Estudios Sociales.
} 
laboriosidad. Lafilosofíanecesita de lanarraciónparano quedarse en conceptos vacíos que producen sistemas totalizantes, aunque tenga la sensación de que todo ejemplo vital traiciona el concepto y puede inducir al equívoco. De todas formas, la filosofía se llena de experiencia y contenido al aproximarse al fenómeno narrativo, lanzándose al mundo del equívoco del que quiere escaparse. Por otro lado, la narración misma, la experiencia narrativa, apela a la filosofía, a riesgo de perder el frescor de la vida. Ricoeur nos propone una solución a esta tensión: la narración "da que pensar" a la filosofía y la filosofía no puede abdicar de esta tarea ofrecida por la narración. Dicho de otro modo, la narración provoca el pensamiento, haciéndola salir de conceptos abstractos fosilizados en un sistema perfecto.

El primer gran aporte del estudio filosófico de la narración o relato es percibir que fraguamos nuestras identidades o subjetividades a través de relatos. Aplicándolo a la acción educativa, podemos postular una primera tarea de una educación: la constitución de subjetividades capaces de acompañar las transformaciones que imponen las peripecias de la vida, o si queremos, los cambiantes contextos culturales.

El modo de comprensión que se pone en juego en la narración, y que podemos llamar inteligencia narrativa o razón narrativa, implica cambiar nuestros esquemas educativos. Estos esquemas pedagógicos narrativos son más adecuados para educar en un mundo diverso y plural, pues el mundo, nuestro mundo globalizado, se mueve en una pluralidad de mundos, en una pluralidad de sentidos y narraciones.

\section{La educación como relato reconfigurador de la propia vida}

Ricoeur analiza la actividad del relato desde una interpretación peculiar de la"mímesis" aristotélica.

La palabra mímesis no significa en la Poética de Aristóteles mera copia de la naturaleza. Su significado singular se remonta más bien a la etimología de la palabra mythos. De acuerdo a la interpretación de Ricoeur, mimesis significa aquí construcción de la trama, propia del poema trágico (Ricoeur, 1987, p. 84). La construcción de la trama asumidas y compartidas, sólo se comprenden narrándose, porque son acontecimientos, cosas que suceden, cosas que pasan en el tiempo, en esa concordancia discordante que son nuestras vidas. Las experiencias humanas son, pues estructuralmente, narrativas; son concatenaciones de acciones desplegadas en el tiempo, donde se va redefiniendo nuestra posición en el mundo, porque provocan nuevas comprensiones de lo que ha sucedido en nuestra vida.

Para desarrollar el modo en que construimos nuestra identidad o subjetividad en el tiempo, Ricoeur nos habla de una triple mímesis (Ricoeur 1987):

- Mímesis I (pre-figuración): las comprensiones y experiencias previas que el lector y el autor de un texto tienen sobre la acción humana como un curso en el tiempo, y que se vehiculan en los símbolos culturales compartidos

- Mímesis II (configuración): se trata de la construcción literaria de una trama, a través de un relato desarrollado temporalmente sobre la historia de una vida

- Mímesis III (refiguración): aplicación del relato a la propia vida, construyendo un nuevo mundo u horizonte de sentido

Se podría estudiar el "acto educativo", la clase concreta o un curso académico como un proceso de configuración (mímesis II) que actúa sobre unas experiencias previas (mímesis I) y provoca un cambio, una transformación en el propio mundo (mímesis III). Esta mímesis que ejerce el acto educativo se produce en los tres protagonistas de la actividad educativa: estudiante, profesor y materia.

La actividad educativa (MII, la clase concreta, el curso) cambia la vida (del estudiante, del profesor, jde la materia!) y la transforma...

Dice Ricoeur que comprender un relato es ver cómo nace de la vida (MI), no es la vida (MII) y, sin embargo, es capaz de cambiar la vida (MIII). Y con la educación, decimos nosotros, pasa lo mismo. Parte de la vida (Ml; del estudiante, de la materia, del profesor), no es la vida (jestamos en clase!) y, sin embargo, cambia la vida, influye en la vida.

\begin{tabular}{|c|l|c|l|}
\hline & \multicolumn{1}{|c|}{ MI } & MII & \multicolumn{1}{|c|}{ MIII } \\
\hline Estudiante & $\begin{array}{l}\text { Viene a clase, con su historia, sus } \\
\text { motivaciones, su vida... }\end{array}$ & $\begin{array}{l}\text { Transformación por la clase/el curso... ya } \\
\text { no es el mismo, puede cambiar su vida... } \\
\text { apropiación }\end{array}$ \\
\hline Materia & $\begin{array}{l}\text { También la materia se presenta en un } \\
\text { determinado momento, hay selección, } \\
\text { intereses }\end{array}$ & $\begin{array}{l}\text { La materia misma también se transforma en el } \\
\text { encuentrodirecto, en la aplicación }\end{array}$ \\
\hline Profesor & $\begin{array}{l}\text { También viene a clase con sus } \\
\text { preocupaciones, experienciasprevias... } \\
\text { suvida... }\end{array}$ & $\begin{array}{l}\text { El profesor también se transforma } \\
\text { narrativamente, vitalmente, se apropia del } \\
\text { actomismo... }\end{array}$ \\
\hline
\end{tabular}

postula el triunfo de la concordancia sobre la discordancia que siempre acompaña a la experiencia vital. Imaginemos algo sencillo para ver lo que está en juego aquí. Llega una persona amiga llorando ante nosotros. La pregunta que brotará en nuestros labios es "¿Qué te pasa?". Esta pregunta apunta al centro de lo que Ricoeur nos quiere proponer. Las experiencias humanas significativas, para ser
Podemos, por tanto, entender la educación como un proceso de mímesis de la vida de los implicados directamente en el acto educativo (Ricoeur, 1984). No se trata únicamente de transformar determinadas áreas cognitivas especializadas, es decir, de crear algo así como "profesionales especialistas de unas técnicas acreditadas por el mercado de trabajo". Se trata de un complejo proceso humano, 
donde los mismos saberes se transforman si consideramos el pensamiento como un proceso abierto en el tiempo, no como la mera repetición de conocimientos establecidos de una vez para siempre.

Ricoeur parte de la relación espontánea y natural que establecemos entre vivir y narrar; de hecho hablamos de la historia de una vida y designamos así el periodo que va del nacer hasta el morir. La estrategia de Ricoeur es someter esta intuición vivida a análisis crítico. Algunas teorías de la narración la definen como ficción, alejándola de la vida. Dice Ricoeur: “.. . la ficción [narración] contribuye a hacer de la vida, en el sentido biológico de la palabra, una vida humana. Quisiéramos aplicar a la relación entre relato y vida la máxima de Sócrates según la cual una vida que no es analizada no es digna de ser vivida"(Ricoeur 1984, p. 45).

La educación es un proceso de crecimiento, de humanización; por eso podemos entenderla como narración. Gracias a la narración examinamos la vida, la analizamos en sentido socrático. Educación y narración confluyen en este proceso de ser personas, proceso de convertirnos en humanos. Intervienen en la humanización; son factores de humanización. Se trata ahora de ver cómo podemos operar con esta imagen de la educación como narración.

Lo primero que nos invita Ricoeur es a diferenciar entre ambos procesos: vivir y narrar. Las historias se cuentan, y no se viven; la vida se vive y no se cuenta.

¿Qué es narrar? Ricoeur nos lo ha resumido brillantemente en "La vida: un relato en busca de narrador" (1984), y luego, en "Tiempo y narración" (1987) aborda el tema de manera extensa. Tiene en cuenta las teorías modernas del relato, pero señalando que lo fundamental ya fue dicho por Aristóteles en su Poética. El concepto más importante que retiene Ricoeur de Aristóteles es el de intriga (trama, mythos), que significa tanto invención como vertebración de una historia. La intriga no es algo estático, sino un proceso dinámico que sólo se realiza (y es una de las tesis de Ricoeur) en el lector/espectador vivo de la historia que se narra.

La educación como acto narrativo es también un proceso dinámico, no estático; de nada sirven las historias que contamos, que cuentan los profesores y sus materias, si los que las escuchan no se implican. De hecho, siguiendo a Ricoeur, podríamos decir que las historias mismas necesitan de los lectores/receptores. ¡Necesitamos de los estudiantes! Son ellos y ellas los que salvan nuestras historias y a nosotros mismos, profesores, como narradores. La educación narrativa se centra en el estudiante como clave de la educación. El estudiante es aquel "ser narrativo" (consuhistoria a medio tramar, jcomo todos!) que en clase escucha historias con las que hace su historia. El profesor es aquel que interviene en este proceso ofreciendo historias-narraciones, siendo él mismo narración-historia viva.

Hay que ver el proceso educativo como imbricación de historias (estudiante, profesor, materia...); historias sin terminar o que si están terminadas se cuentan de otro modo, adquieren un nuevo sentido. Por eso, ver la educación como proceso narrativo es verla como un proceso de emergencia de sentidos, de innovación, creatividad, imaginación o, dicho con una palabra de Hannah Arendt, como nacimiento. Educar narrativamente es ofrecer nacimientos... (de los estudiantes, de las ideas-historias... iy de nosotros mismos, el profesorado!)

La intriga-trama se presenta como una síntesis de elementos heterogéneos. Esto resulta vital tanto para el acto educativo (que hemos circunscrito al aula), como a la acción educativa (que se refiere al conjunto del currículo; ver Barone-Mella, 2003). Nos propone un proyecto no fragmentado de configuración de la persona, sin caer en un ideal totalizador y autoritario. En primer lugar, la intriga-trama es una síntesis de acontecimientos diversos; transforma la diversidad de acontecimientos en la unidad de una historia completa; es más que la sucesión o enumeración caótica de acontecimientos. En segundo lugar, la intriga-trama une los elementos diversos (circunstancias, agentes, pacientes, interacciones...)sindiluirlosengrandescategorías; esunatotalidad a la vez concordante y discordante, es "concordancia discordante" (Ricoeur 1984, p. 47). A esta unidad de concordancia/discordancia corresponde por parte del lector una comprensión peculiar: el acto de seguir una historia, que es "una operación compleja".

Esta operación compleja, como puede verse claramente, se debe al respeto de las singularidades sin perderse en el caos de la enumeración contigua de cosas. En ese sentido, la tarea de la educación es también un esfuerzo en este tipo de comprensión de lo singular, sin pretender únicamente la explicación categórica, la teorización establecida de una vez para siempre. Enseñamos la capacidad de seguir una historia, la capacidad de entender historias, la capacidad de producir historias y, más importante, la capacidad de construir la propia historia. Estamos ayudando a lo que Ricoeur (2008) llama en una de sus últimas obras, Lo justo 2, "coherencia narrativa". La educación narrativa es una "educación para la coherencia narrativa"; una educación en la identidad narrativa... tarea compleja.

Entercer lugar, la trama-intriga es la síntesis de dos temporalidades: la temporalidad de la sucesión (y luego, y luego...) y la temporalidad de la integración, de la culminación(el kairós del Nuevo Testamento), de la configuración. Dice Ricoeur: "Yo diría en este sentido que componer una historia es, desde el punto de vista temporal, extraer una configuración de una sucesión"(Ricoeur, 1984, p. 47).

Esta comparación entre educación y narración o mímesis nos lleva a concluir que la principal tarea de la actividad mimética está orientada a poder vivir el transcurrir de la existencia, la vida, como una construcción del sentido de nuestras personas en el tiempo, uniendo peripecias discordantes.

\section{La educación narrativa como enseñanza para vivir éticamente}

Así entendida, toda trama comporta ciertos elementos de inteligibilidad, o como decía Aristóteles, toda historia bien contada enseña algo, y enseña aspectos universales de la condición humana. A ese tipo de comprensión que se pone en juego al contar historias (componer historias, educar con historias) se puede llamar "inteligencia narrativa, que está mucho más cerca de la sabiduría práctica y del juicio que de la ciencia"(Ricoeur 1984, p. 48).

La narración es una buena ayuda para la ética, pues con la narración "proponemosalaimaginaciónyalameditacióncasosimaginariosque constituyen otras tantas experiencias de pensamiento mediante las cuales aprendemos aunir losaspectoséticos de la conductahumana 
con la felicidad y la desgracia, la fortuna y el infortunio" (Ricoeur 1984, p. 48). Dicho de modo sentencioso, la educación narrativa es una educación moral crítica, reflexiva e imaginativa.

El tipo de inteligencia del relato es el de la inteligencia phronética y no teórica. Podemos hablar de una inteligencia narrativa. La educación narrativa consistiría en el desarrollo de la inteligencia narrativa. Tomaría en cuenta la triple mimesis del acto educativo, para que el proceso educativo como tal se convierta en un relato de la propia vida de todas las personas implicadas en el proceso de enseñanza-aprendizaje.

\section{Del relato a la vida}

El relato, nos dice Ricoeur, conduce a la vida. La configuración del relato no se realiza en la obra sino en el lector, en la vida del lector. "El sentido o el significado de un relato brota en la intersección del mundo del texto con el mundo del lector"(Ricoeur 1984, p. 51).

El educador en inteligencia narrativa (su disciplina es historia y narración) intentará que sus historias lleguen a los estudiantes, tengan eco en ellos y ellas; en esa intersección del estudiante con la historia brota el sentido; se trata del acontecimiento del sentido, el acontecimiento de la educación. El relato puede transfigurar la experiencia del lector y de igual manera la educación, lo que enseñamos, puede transfigurar la experiencia del estudiantado.

Toda obra literaria permite abrir delante de ella un horizonte de experiencia posible, "un mundo en el cual sería posible habitar" (Ricoeur 1984, p. 51). Ricoeur denomina "mundo del texto" a este horizonte posible de experiencia abierto por el texto literario. El arte de comprender un texto (y aquí consideramos "la materia enseñada" como un texto) ha de pasar por la fusión de horizontes (Gadamer) entre el lector y el horizonte de experiencia que abre la obra.

La educación narrativa supone también ese esfuerzo de fusión de horizontes entre el horizonte de nuestros estudiantes y el horizonte de nuestra materia/nuestras historias. Puede comprenderse como un esfuerzo de traducción. Llevar las preocupaciones del estudiante a nuestra materia y llevar las preocupaciones de nuestra materia al estudiantado. Un camino de acercamiento que recorren ambos, materia y estudiantes, y que nosotros, profesores, en esta inteligencianarrativa, intentamos propiciar.Eslanuevamayéutica del profesorado que busca desarrollar este tipo de inteligencia práctica, complementaria y profundizadora de la inteligencia teórica.

En la hermenéutica ricoeuriana, un texto no es un conjunto muerto de palabras consignadas por escrito, y que yace en bibliotecas hasta que un ojo curioso lo desempolva como cosa del pasado. Un texto "es una mediación entre el hombre y el mundo, entre el hombre y el hombre, y entre el hombre yél mismo. La mediación entre el hombre yelmundo es lo que se denomina referencialidad; la mediaciónentre el hombre y el hombre es la comunicabilidad; la mediación entre el hombre y él mismo es la comprensión de si" (Ricoeur, 1984, 51-52).

Atendiendo a los elementos de esta comprensión de un texto, la educación narrativa, nuestro trabajo con/bajo esta forma de inteligencia, busca: 1) ampliar referencialidad (más mundo para nuestros estudiantes), 2) ampliar comunicabilidad (más humanidad y socialidad para ellos, más diálogo con otros) y 3) comprensión de sí (que se entiendan mejor a sí mismos... que puedan narrar su propia historia).

Como consecuencia, se trataría también de luchar contra otras formas, directas o indirectas, de educación: aquellas que se limitana la referencialidad descriptiva (esto es lo que hay), a la comunicación utilitaria (¿y esto para qué?) y a la comprensión narcisista (yo sólo hago lo que me gusta).

\section{De la vida biológica a la vida biográfica: la identidad narrativa}

La vida no es más que un fenómeno biológico hasta que no es interpretada, y en la interpretación, la ficción, la narración, van a jugar un papel importante. Educación narrativa es que nuestros estudiantes pasen de una vida biológica a una vida biográfica... narrativa.

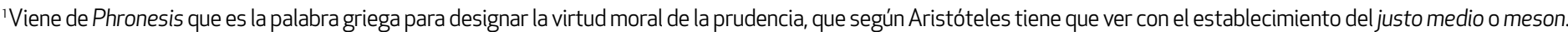

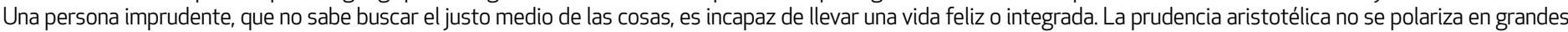
principios morales abstractos, sino que pondera lo apropiado para cada caso. Es una virtud eminentemente práctica y cercana a la vida cotidiana.

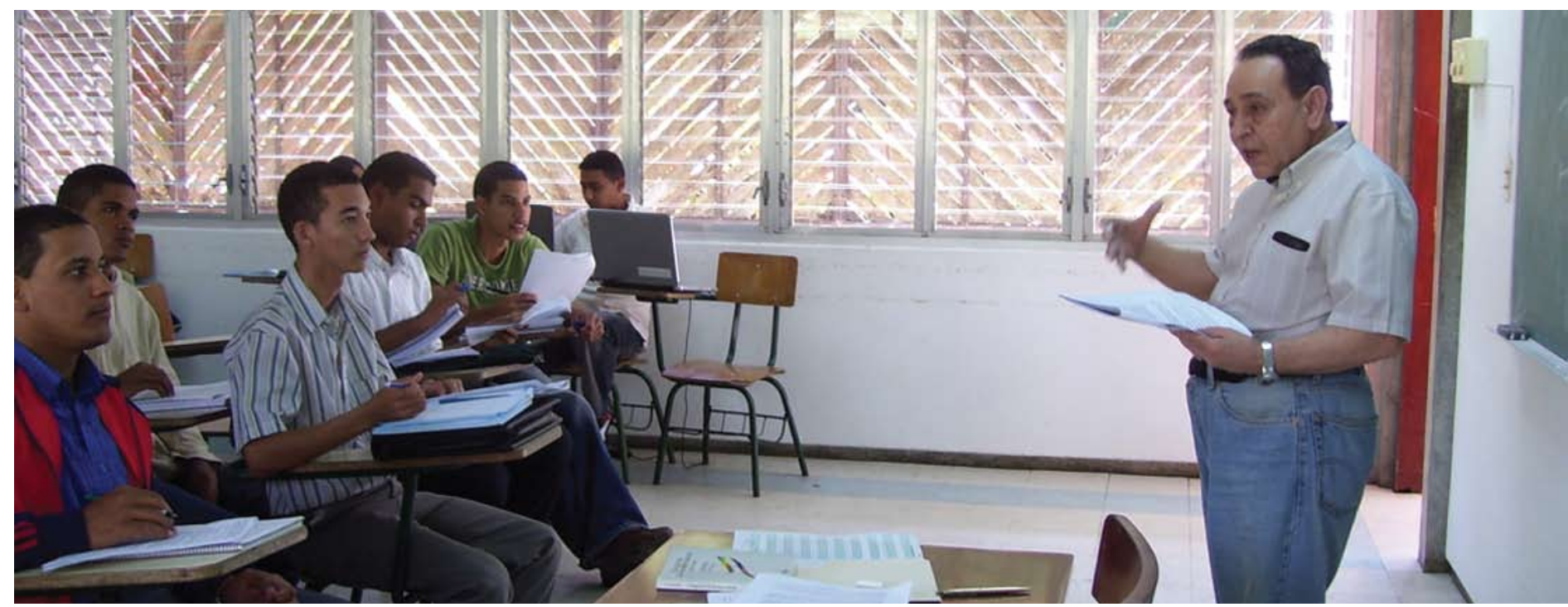


La narración es una mímesis de la vida; la vida es imitada por la narración. En la experiencia viva hay elementos de anclaje de lo narrativo, elementos que posibilitan la "inserción de lo narrativo y cuya necesidad quizás expresa" (Ricoeur, 1984, p. 53).

Las acciones humanas se dan en una "semántica de la acción", en una red nocional muy distinta a la de los movimientos físicos. Esta red nocional es precisamente la que entrará en juego en el relato (agentes, acciones, pacientes, circunstancias). Así, el conocimiento no sería algo caído del cielo de las ideas, un saber de los expertos dioses, sinolaconstrucciónpaciente. Esloheterogéneo delasíntesis en que hacemos consistir la trama de un relato. De ahí que:"la misma inteligencia phronética preside la comprensión de la acción (y de la pasión) y la comprensión del relato" (Ricoeur, 1984, p. 53).

Para Ricoeur "La ficción narrativa es una dimensión irreductible de la comprensión de sí.... Si es cierto que la ficción no se realiza sino en la vida y que la vida solamente se comprende a través de las historias que narramos sobre ella, resulta que una vida examinada es una vida narrada" (Ricoeur, 1984, p. 55).

Inspirándonos en estas frases, podemos poner como tarea de la educación el ayudar a examinar la vida, que es lo mismo que ayudar a narrar la vida. ¿Cómo? Dando claves, recursos, elementos para narrar, para hacer esas síntesis (si se puede, o al menos intentarlo) de lo heterogéneo. Esta "síntesis de lo heterogéneo" es muy necesaria en estos tiempos del "mosaico de conocimientos" que produce la interconectividad por Internet. Más que nunca urge esta facultad de síntesis de lo heterogéneo en la acción educativa.

Nuestra vida es un esfuerzo de actividad constructiva en la que mediante la inteligencia narrativa intentamos reencontrar, y no imponer desde fuera, "la identidad narrativa que nos constituye" (Ricoeur, 1984, p. 57). La identidad narrativa que emana de una inteligencia narrativa no se cristaliza como una sustantividad cerrada, inaccesible al devenir, pero tampoco como una sucesión incoherente de acontecimientos.
En último término, pues, estamos avocados a definir nuestra subjetividad por la identidad narrativa. Narramos nuestra vida, nuestra historia, aunque no seamos totalmente autores de nuestra vida. Esta es la gran diferencia entre la vida y la ficción; en la vida no somos totalmente autores. La educación narrativa puede colaborar a establecer este sano límite que nos despoja de todo sentimiento de omnipotencia, que amenaza toda convivencia pacífica y creativa.

El estudiante que viene a nuestras clases no "está dado desde el principio", se hace, se construye en el acto educativo mismo. El acto educativo es acto narrativo porque ayuda a configurar las experiencias discordantes de nuestros estudiantes. La narración hace que veamos la educación como un proceso global dinámico; no algo sustancial, cerrado y clausurado. Ya no nos permite pensar la educación como trasvase de unos conocimientos, con los que rellenamos a unos estudiantes que lo asimilan como meros receptáculos vacíos, por un profesor cargado de saber que los transmite. Descubrimos que los estudiantes no están ahí como tábulas rasas, ni los profesores dominan, como muchos creen, un conjunto de conocimientos que están ya dados para siempre y de los cuales son sus canes cerveros.

\section{Referencias bibliográficas}

Bárcena, F. \& Mèlich, J.C. (2000). La educación como acontecimiento ético. Natalidad, narración y hospitalidad. Barcelona: Paidós.

Barone, S.\&Mella, P. (2003). Acción educativa y desarrollo humano en la universidad de hoy. Revista Iberoamericana de Educación, 31, 187-218.

Ricoeur, P.(1984). La vida:unrelato en busca de narrador. En:Educación y Política. (pp. 45-58). Buenos Aires: Docencia.

Ricoeur, P. (1987). Tiempo y narración I. Configuración del tiempo en el relato histórico. Madrid: Cristiandad.

Ricoeur, P. (2008). Lo Justo 2. Estudios, lecturas y ejercicios de ética aplicada. Madrid: Trotta.

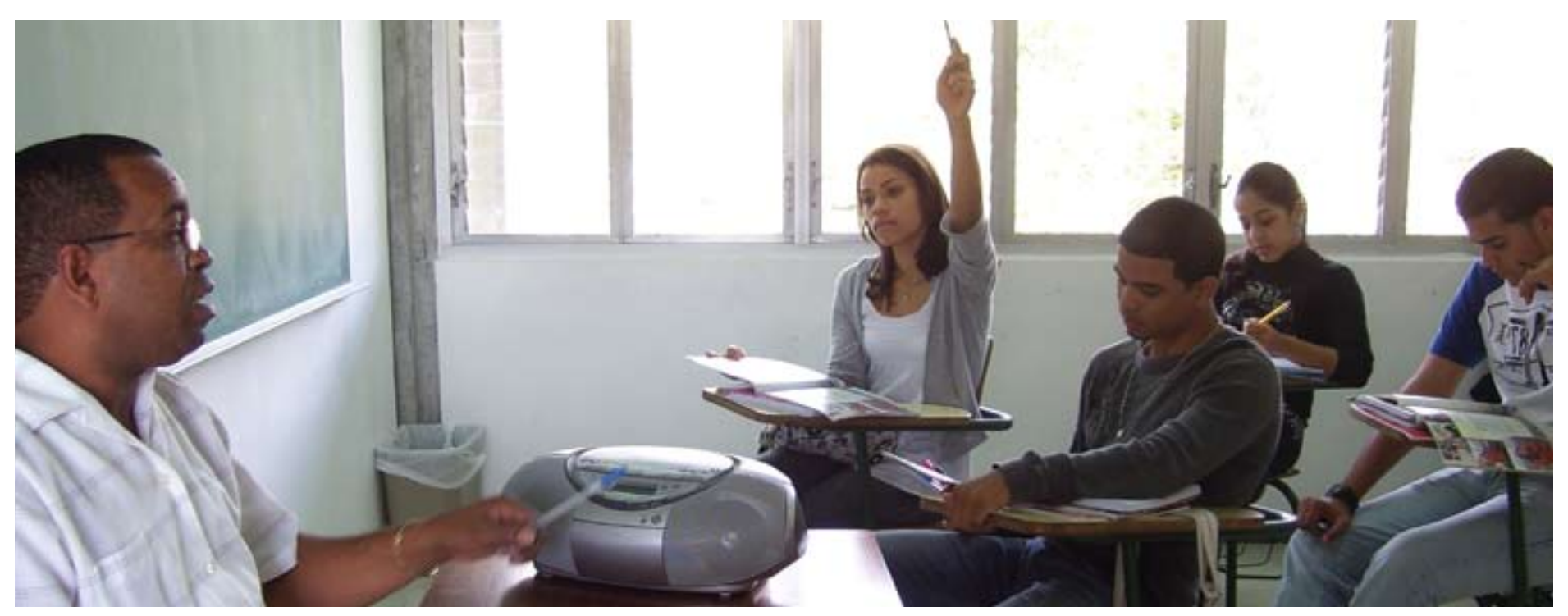

